\title{
OS ESTUDOS LINGUÍSTICOS E A CONSTITUIÇÃO DE OBJETOS DE DISCURSO: OS CONCEITOS DA LINGUÍSTICA TEXTUAL COMO REFERÊNCIA PARA O TRATAMENTO TEÓRICO-ANALÍTICO DA ESCRITA ESCOLAR
}

\begin{abstract}
Emerson de PIETRI
- RESUMO: Neste artigo, apresentam-se resultados de pesquisa cujo objetivo é investigar o processo de constituição da escrita escolar em objeto dos estudos linguísticos. Seguindo-se orientação teórica filiada à Análise do Discurso de linha francesa, analisaram-se relatórios de pesquisas desenvolvidas na primeira metade da década de 90 do século XX, em programas de pós-graduação de universidades públicas paulistas. A circunscrição metodológica do corpus se fez de modo a considerar um espaço de relações interdiscursivas específicas que se apresentaram entre os discursos acadêmico, pedagógico e oficial, no Estado de São Paulo, desde os anos finais da década de 70 do século XX. A análise dos dados evidenciou a referência, no momento histórico observado, a uma memória já constituída do discurso acadêmico sobre a escrita escolar, produzida nas décadas de 70 e de 80. Mostrou também que elementos teóricos da linguística textual referenciaram a mobilização de perspectivas teóricas dos estudos linguísticos para o tratamento da escrita escolar nas pesquisas observadas. A consolidação de uma memória discursiva própria ao discurso acadêmico e a estabilidade da noção de texto elaborada pela linguística textual constituíram índices para a delimitação e distanciamento, nesse discurso, dos espaços do acadêmico e do escolar.
\end{abstract}

- PALAVRAS-CHAVE: Análise do Discurso. Linguística textual. Escrita escolar.

\section{Introdução ${ }^{1}$}

No presente trabalho, observa-se o processo de constituição da escrita escolar em objeto de pesquisa de dissertações e teses, em programas de pós-graduação de universidades brasileiras, procurando-se caracterizar a (re)ordenação das bases semânticas dos discursos sobre ensino de língua portuguesa que se operaram no início da década de 90 do século XX, consideradas as diferenças que se percebem em relação às duas décadas anteriores. O objetivo é o de caracterizar os modos de constituição da escrita escolar em objeto dos estudos linguísticos nesse momento histórico, em que já havia uma memória discursiva produzida, fato que possibilitou

* USP - Universidade de São Paulo. Faculdade de Educação. São Paulo - SP - Brasil. 05541-030 - pietri@usp.br

1 O presente trabalho foi elaborado a partir do relatório resultante de pesquisa financiada pelo CNPq (Processo n.: 400540/2008-8). 
rearranjos específicos nos processos de delimitação recíproca dos discursos em concorrência e, consequentemente, a redefinição dos temas, das estratégias argumentativas e dos conceitos em relação na formação discursiva considerada.

O corpus de análise foi produzido com o trabalho metodológico sobre dissertações de mestrado e teses de doutorado que possuem como objeto de investigação o texto escrito produzido em contexto escolar de ensino básico, compreendido este como o período entre a $5^{a}$ série do Ensino Fundamental e o $3^{\circ}$ ano do Ensino Médio, na antiga nomenclatura. Excluíram-se, assim, pesquisas sobre escrita escolar voltadas para ensino de caráter supletivo, ou em nível de $3^{\circ}$ grau. O objetivo do estabelecimento desse recorte foi o de garantir que as pesquisas componentes do corpus se referissem ao nível da escolarização básica que fosse objeto das proposições curriculares oficiais publicadas no período em questão, e, também, às proposições acadêmicas para o ensino de língua portuguesa destinadas à escolarização básica regular. Desse modo, as relações entre os discursos acadêmico, pedagógico e oficial seriam observadas segundo um princípio mais controlado para o recorte do espaço discursivo a ser observado, dado que os documentos representativos dos três discursos em relação se produziriam em função de um campo disciplinar comum - o ensino de língua portuguesa na escolarização básica regular.

Respeitando-se o mesmo princípio estabelecido para o recorte do espaço discursivo de interesse para a análise, decidiu-se restringir a coleta do material de análise aos programas de pós-graduação do Estado de São Paulo, na tentativa de obter maior organicidade na composição do corpus em si, consideradas, como mencionado, as relações do discurso acadêmico com o oficial e o pedagógico: no momento histórico em questão, as três décadas finais do século XX, houve um importante movimento de produção e publicação, por instâncias oficiais responsáveis pela Educação no referido Estado, de documentos de referência para o ensino (Propostas e Guias Curriculares, e Subsídios a eles). Ainda que na década de 90 a produção de diretrizes curriculares oficiais já se fizesse mais ampla e regularmente na Federação, optou-se por se manter restrita a observação à produção existente no Estado de São Paulo, de modo a garantir-se a perspectiva de continuidade em relação à observação do processo de constituição da escrita escolar em objeto de discurso nas duas décadas anteriores (décadas de 70 e de 80), momentos também considerados no percurso de pesquisa em que se insere o presente trabalho. Restringe-se, portanto, a extensão do conjunto do corpus em razão dos critérios estabelecidos para o recorte do espaço discursivo a ser observado, mas se confere maior produtividade a esse corpus ao se definir sua extensão em relação ao processo de delimitação recíproca que se estabelece entre os discursos acadêmico, pedagógico e oficial, componentes do espaço circunscrito para análise. 
Os marcos temporais para a definição do período em análise compreendem, assim, a publicação dos primeiros estudos acadêmicos sobre escrita escolar, na segunda metade da década de 70 (PIETRI, 2007a), que se faz desde proximamente à publicação dos Guias Curriculares para o Ensino de $1^{\circ}$ Grau (SÃO PAULO, 1975); seguidos da publicação da Proposta Curricular para o Ensino de Língua Portuguesa: $1^{\circ}$ grau (SÃO PAULO, 1986), num momento em que uma série de pesquisas acadêmicas caracterizadas pela referência à sociolinguística e/ou ao sociointeracionismo são desenvolvidas (PIETRI 2007b, 2012b); ao momento da publicação dos Parâmetros Curriculares Nacionais (BRASIL, 1997), que alteram substancialmente os referenciais teóricos e metodológicos para o ensino de língua portuguesa até então em circulação e, portanto, sinalizam o momento final do período estudado. No presente trabalho, observa-se o período correspondente aos anos iniciais da década de 90 , em que se desenvolveram pesquisas não mais orientadas por perspectiva sociolinguística e/ou sociointeracionista (limite para com relação ao momento histórico imediatamente anterior), nem por noções como as de gêneros de discurso ou de letramento (limite para com relação ao momento histórico posterior).

Uma vez que se trata de observar relações entre discursos, a noção de interdiscurso, tal como elaborada por Maingueneau (2005), é o ponto de partida para o tratamento a ser realizado do material de análise do presente estudo. A concepção de interdiscursividade proposta pelo autor contribui para a observação do processo de constituição da escrita escolar em objeto dos estudos acadêmicos em razão de esse processo consistir no trabalho de discurso(s) sobre discurso(s), neste caso específico, entre os discursos acadêmico, pedagógico e oficial, num processo de delimitação recíproca.

Segundo a perspectiva em questão, os enunciados de um discurso se constituem com base em regras semânticas específicas, que definem seu pertencimento a um dado discurso, regras que definem também enunciados que lhe são estranhos. O sistema de restrições semânticas é concebido como um modelo de competência discursiva, e os enunciadores de um discurso dado apresentam o "[...] domínio tácito de regras que permitem produzir e interpretar enunciados que resultam de sua própria formação discursiva e, correlativamente, permitem identificar como incompatíveis com ela os enunciados das formações discursivas antagonistas." (MAINGUENEAU, 2005, p.23). Considera-se assim como unidade de análise não o discurso (entendido como "[...] dispersão de textos cujo modo de inscrição histórica permite definir como um espaço de regularidades enunciativas." (MAINGUENEAU, 2005, p.15)), mas um espaço de trocas entre vários discursos convenientemente escolhidos, o que supõe, portanto, a precedência do interdiscurso sobre o discurso. 
A escolha dos discursos a serem analisados se realiza, segundo Maingueneau (1997, p.116), a partir do trabalho em relação a uma conjunção espacial que se organizaria em três diferentes dimensões: o universo discursivo, o campo discursivo e $\mathrm{o}$ espaço discursivo. $\mathrm{O}$ universo discursivo corresponderia ao "[... conjunto de formações discursivas de todos os tipos que coexistem, ou melhor, interagem, em uma conjuntura." Seria um conjunto finito, mas irrepresentável em sua totalidade, tendo função metodológica enquanto noção em que se recortam os campos discursivos. Campo discursivo é definido como "um conjunto de formações discursivas que se encontram em relação de concorrência, em sentido amplo, e se delimitam, pois, por uma posição enunciativa em uma dada região". Já o espaço discursivo seria o resultado da delimitação de "[...] um subconjunto do campo discursivo, ligando pelo menos duas formações discursivas que, supõese, mantêm relações privilegiadas, cruciais para a compreensão dos discursos considerados." (MAINGUENEAU, 1997, p.117). Faz-se necessário ao analista do discurso, portanto, operar um recorte, fundamentado em recursos metodológicos que podem ser encontrados em estudos historiográficos, de modo a definir o espaço discursivo produtivo para a análise a ser realizada. A produtividade se relaciona à possibilidade de caracterizar o sistema de regras semânticas que ordena globalmente um determinado discurso.

Segundo Maingueneau (2005, p.22), “[...] o caráter 'global' da semântica discursiva se manifesta pelo fato de que ela restringe simultaneamente 0 conjunto dos 'planos' discursivos: tanto o vocabulário quanto os temas tratados, a intertextualidade ou as instâncias de enunciação [...]". Nesse sentido, trabalhase com a hipótese de que a determinados discursos correspondem estruturações textuais específicas, isto é, que os gêneros textuais estão em concordância com a semântica de uma dada formação discursiva. Assim, a observação dos modos como se compõe materialmente o discurso constituiria um meio para a caracterização do(s) discurso(s) em que o(s) texto(s) se inscreve(m).

Parte-se da proposta de Adam (2008), fundamentada em Maingueneau (1995), quanto ao fato de o texto trazer em si índices das condições de enunciação em que se produziu. A referência constituída com base nesses índices garante a definição de um espaço e de um tempo para os dizeres, e, com isso, a possibilidade de movimento dos sujeitos para a configuração dos objetos de discurso. Assim, podem ser colocadas as seguintes questões: de que modo se constituíram as condições de enunciação num dado momento histórico? Como se estabeleceram índices de pessoa, funções e relações de tempo e espaço nessas condições? Que posições de sujeito foram projetadas e que objetos se produziram com seu (das condições de enunciação) funcionamento?

O trabalho de análise, na presente investigação, se volta, portanto, para os modos como os sujeitos se movimentam em relação a determinados índices 
de tempo, de espaço e de pessoa, e como operam recortes e apropriações, com esse movimento, para a definição de uma perspectiva teórica específica para o tratamento da escrita escolar.

A hipótese com que se trabalha é a de que as pesquisas sobre escrita escolar desenvolvidas no momento histórico observado se caracterizam por considerar à distância fatores próprios à escolarização: isto é, não há proximidade entre pesquisador e professor, como havia nas pesquisas desenvolvidas no momento histórico anterior (PIETRI, 2012b), mas a definição de uma diferença entre um e outro desses sujeitos, que ocupam espaços também distintos que não se interseccionam - a academia e a escola. O professor ocupa nesse processo um lugar ambíguo: de sujeito de quem se fala, quando se tematiza sua formação e seu trabalho nas condições de produção escolares; e de sujeito para quem se fala, quando a ele se destinam propostas didáticas e subsídios teóricos que o auxiliassem a suprir lacunas de formação ou a alterar práticas de ensino de modo a torná-las satisfatórias. A tematização das relações da academia com a escola teria possibilitado assim a constituição da escrita escolar em objeto de pesquisa.

No período observado, o dispositivo que sustenta o movimento analítico se fundamenta na referência a uma memória já constituída de um discurso sobre ensino de português no país e, mais especificamente, sobre escrita escolar. Compreendese memória, aqui, com referência "[...] aos tipos de relações intertextuais que a competência discursiva define como legítimas." (MAINGUENEAU, 2005, p.81). Trata-se dos modos como um discurso se relaciona com discursos anteriores do mesmo campo, e, também, do "[...] passado específico que cada discurso particular constrói para si, atribuindo-se certas filiações e recusando outras." (MAINGUENEAU, 2005, p.81). O autor denomina intertextualidade interna ao trabalho da memória discursiva no interior de um dado campo.

À memória discursiva sobre escrita escolar, associam-se, no período estudado, elementos da linguística textual, cuja noção de texto possibilita o tratamento do material de análise das pesquisas sem que fosse necessária a inserção do pesquisador no contexto escolar: a unidade textual, sustentada em processos de referenciação, guardaria em si elementos do contexto em que produzida. A não necessidade, proporcionada pela noção de unidade textual, do tratamento da referência em contexto e a fundamentação dos dizeres numa memória do discurso acadêmico sobre produção escrita seriam os fatores a possibilitar a delimitação e o distanciamento entre os espaços do acadêmico e do escolar.

Os dados a serem analisados neste momento foram produzidos, portanto, com base na observação dos princípios de ordenação da situação enunciativa acima referidos (a filiação dos dizeres a uma memória já constituída do discurso acadêmico sobre a escrita escolar, associada a elementos da linguística textual, cujas noções de texto e de referenciação possibilitam a definição dos limites 
entre o acadêmico e o escolar, e, em consequência, determinada disposição dos sujeitos e dos objetos da enunciação). Com o objetivo de manter em perspectiva a série histórica, as considerações realizadas a partir dos trabalhos analisados serão apresentadas respeitando-se a sequência temporal de suas publicações.

\section{Os referenciais históricos para a definição do espaço discursivo em análise}

A escrita escolar se constituiu em objeto dos estudos linguísticos recentemente no Brasil. Publicaram-se nos anos finais da década de 70 do século XX os primeiros trabalhos voltados para a análise de redações escolares (PIETRI, 2007a). Nesse período de emergência, desenvolveram-se também investigações sobre o tema em Programas de Pós-Graduação, no Estado de São Paulo. Um elemento comum a essas investigações foi a consideração de que os problemas encontrados nas redações escolares constituiriam sintomas de uma situação geral das condições do ensino e da aprendizagem nas escolas do ensino básico (PIETRI, 2012a). A referência a uma suposta crise na linguagem funcionou como elemento discursivo em que se sustentou a própria possibilidade da investigação, pois indicava um ponto de partida para o trabalho investigativo, uma vez que se faria necessário, com base em tal diagnóstico, buscar as causas da suposta crise, recorrendo-se, então, a subsídios teóricos para a realização do trabalho de produção e análise dos dados.

As causas apontadas para os problemas de escrita foram percebidas pelos pesquisadores segundo estivessem ou no interior da escola, quando se consideravam as condições históricas de produção dos textos e o tipo de relação do sujeito com as condições em que se encontrava (no caso, marcado pela passividade); ou no exterior da escola, quando as referidas causas foram atribuídas à sociedade de massas, à indústria cultural e à função social, política e ideológica da escola numa sociedade de classes. O movimento do pesquisador, entre um e outro desses dois polos, possibilitou o acesso, ora a teorias explicativas fundadas em recursos teóricos da psicologia (para se considerar as condições do sujeito), ora aos estudos sociológicos e culturais (para se pensar sobre as condições mais amplas em que se inseriam a escola e o aluno). No realizar desse movimento entre um polo e outro - do subjetivo e do social - tornou-se possível, portanto, a apropriação de recursos para a constituição da escrita escolar em objeto de análise, num momento em que não se encontravam elaboradas suficientemente bases teóricas linguísticas adequadas ao tratamento da linguagem em sua modalidade escrita (PIETRI, 2012a).

Em relação à década de 80 do século XX, e à questão sobre que condições enunciativas possibilitaram a constituição da escrita escolar em objeto de 
investigações acadêmicas, a hipótese com que se trabalha é a de que esse processo se realizou em função de os trabalhos de pesquisa desenvolvidos nesse momento se caracterizarem por considerar a relação entre fatores internos e externos à escolarização, num movimento em que se associaram, aos primeiros, os fatos de oralidade, e aos segundos, os elementos da escrita. A tematização das relações da escola com seu exterior teria possibilitado assim a constituição da escrita escolar em objeto de pesquisa. Nesse período, o movimento analítico se fundamentaria entre posições marcadas em pares opositivos, como o par /oralidade x escrita/, relacionado ao par /diferença linguística x norma linguística/, que se associam, por sua vez, a outro par opositivo baseado na contraposição /condições de produção intraescolares x condições de produção extraescolares/. Havia, então, intersecção dos espaços do acadêmico e do escolar; pesquisador e professor se aproximavam, muitas vezes se confundiam, principalmente em pesquisas qualitativas de caráter interventivo, quando o professor na sala de aula era o pesquisador na academia (PIETRI, 2012b).

Já na primeira metade da década de 90 do século XX, as considerações sobre a escrita escolar se realizaram em resposta a questões que seriam apresentadas pelas condições do ensino em contexto escolar. Os problemas encontrados no texto escrito produzido na escola seriam decorrentes dos modos de produção encontrados nesse lugar institucional, e não de fatores próprios à sociedade mais ampla, como se apontava na década de 70.

No mesmo sentido, a relação entre elementos intra e extraescolares, importante fator para as considerações sobre escrita escolar na década de 80, perde valor nos anos iniciais da década seguinte: os trabalhos se voltam então para a aplicação de uma perspectiva teórica específica para o tratamento do texto na escola - diferentemente do que acontecia antes, quando uma perspectiva teórica era acionada para promover mudanças nas condições de produção do texto em sala de aula (centradas na escrita), de modo a contrastá-las com as condições de produção do texto no exterior da escola (centradas na oralidade).

A referência aos fatores extraescolares, nos trabalhos produzidos nos anos iniciais da década de 90, tem como sua fonte os resultados das investigações realizadas nas décadas anteriores. Há, assim, nesse período, um conjunto de saberes acadêmicos sobre escrita escolar que compõe já uma memória: trata-se, então, não mais de um momento de emergência da escrita escolar em objeto do discurso acadêmico, mas de um momento em que o discurso acadêmico sobre a escrita escolar encontra-se com seus limites estabelecidos, constituindo-se em formação discursiva cuja identidade se elabora em processos de delimitação recíproca para com discursos concorrentes.

O discurso acadêmico sobre escrita escolar, no momento histórico em questão, se caracteriza por definir suas diferenças para com o discurso 
pedagógico e o discurso oficial. Nesse processo de delimitações, contrapõem-se concepções de linguagem e de ensino. Assim, percebe-se haver concorrência entre as concepções elaboradas pelos estudos linguísticos, que fundamentam as investigações acadêmicas, e aquelas atribuídas, nessas investigações, à cultura escolar.

O professor é o referente principal para as discussões em relação à satisfatoriedade ou não das bases teóricas que fundamentam a prática de ensino em sala de aula. A formação docente é, assim, o índice que possibilita a tematização do espaço intraescolar nos limites próprios ao discurso acadêmico, de modo a marcarem-se os limites entre academia e escola. Trata-se, portanto, da representação do intraescolar como um espaço para o qual se projetam as possibilidades que teorias linguísticas ofereceriam para práticas de sala de aula e a formação do professor.

\section{Os problemas da escrita escolar diagnosticados}

Uma das principais características do período em análise é a mobilização, nas investigações então realizadas, de uma perspectiva teórica específica para o tratamento do material de análise (em lugar da associação de diferentes perspectivas teóricas, de campos diversos, como se observa nas duas décadas anteriores). O referencial teórico mobilizado fundamentou o trabalho de análise de dados e de proposição de saberes que pudessem contribuir para alterar as condições de produção de textos escritos na escola e promover a melhoria na qualidade destes.

A noção de texto, fundamentada explicitamente em elementos da linguística textual, é o referente principal a que se associam as concepções teóricas específicas que fundamentaram as investigações então realizadas. Esse é um dado importante a respeito dos documentos em análise, pois a circunscrição dos contextos de pesquisa e de ensino, de modo a projetá-los distanciados e independentes um do outro, parece ser possível em razão da autonomia que o texto, uma vez produzido, teria em relação às condições de produção: a possibilidade de tratar o texto em sua unidade material, sem a necessidade de referir elementos externos a ele, dado que ele traria em sua constituição a representação de elementos das condições de produção, garante coerência à proposta de transposição de elementos teóricos da academia para a escola com o objetivo de solucionar os problemas da escrita escolar. Isto é: seria possível avaliar a qualidade dos textos escritos produzidos em contexto escolar com base na própria materialidade textual. No mesmo sentido, seria possível diagnosticar e propor mudanças nas condições de produção escolares dos textos sem que fosse necessário ao pesquisador se fazer presente no contexto escolar a ser investigado: a fundamentação em e a proposição de 
subsídios teóricos adequados à pesquisa e ao ensino seriam suficientes para promover as mudanças necessárias para a melhoria da produção textual escrita.

A falta diagnosticada em contexto escolar adviria, como se afirma nos relatórios de pesquisa analisados, da não implementação, de fato, das propostas de ensino já então existentes, fundamentadas na noção de texto e apoiadas na ideia de que a qualidade do texto guardaria em si características do modo como concebida a produção de textos em contexto escolar. Os problemas da escrita escolar teriam suas causas, assim, no fato de que os professores não teriam se apropriado das concepções de linguagem e de ensino, centradas na noção de texto, em circulação desde a década de 80 em propostas acadêmicas e oficiais.

As pesquisas se sustentaram em três elementos que compunham então a memória discursiva sobre escrita escolar: a relação oralidade/escrita; as condições de produção textual na escola (e as relações com fatores sociais, políticos e econômicos); a prevalência do senso comum nas redações. A esses elementos, associaram-se aspectos desenvolvidos pela linguística textual: a prevalência do senso comum, decorrente das condições de produção escolares do texto escrito, se evidenciaria na falta de informatividade e de progressão textual, característica das redações escolares; dificuldades para o tratamento da relação oralidade/ escrita se mostrariam na (in)adequação do texto ao contexto de sua produção e se caracterizariam textualmente em problemas de coesão e de coerência. ${ }^{2}$

Nota-se, portanto, nesse momento: a) a consolidação da proposta de que o texto é a unidade de sentido adequada ao tratamento teórico e prático nas discussões em torno do ensino de língua portuguesa na escola; b) o apoio na concepção de texto como unidade de sentido para a proposição de uma perspectiva teórica específica que fundamentasse a pesquisa sobre a escrita produzida em contexto escolar.

O tratamento das condições de produção textual na escola com base numa perspectiva teórica específica garantiria soluções para os problemas diagnosticados nos textos, e, consequentemente, contribuiria para a melhoria da qualidade das produções escritas escolares. Compõe-se, assim, um dispositivo que possibilita a associação de fatos da memória discursiva sobre escrita escolar a elementos produzidos mais então recentemente pelos estudos do texto. A partir dessa associação, produzem-se condições para a proposição de alternativas pedagógicas fundamentadas em perspectivas teóricas específicas do campo dos estudos linguísticos.

2 É importante destacar que as referências à Linguística Textual aparecem, em teses e dissertações sobre escrita escolar, desde os anos finais da década de 70, e acompanham o processo, relatado no artigo de Koch (1999), de consolidação dos estudos do texto em contexto brasileiro. 


\section{Da delimitação das condições escolares de produção textual}

Nas pesquisas sobre escrita escolar, desenvolvidas na primeira metade da década de 90, aponta-se que as causas dos problemas de redação se encontrariam nas condições de produção textual existentes na escola, que não permitiriam a elaboração, pelo aluno, de uma concepção adequada de texto. Essas causas, evidenciadas em investigações acadêmicas sobre escrita escolar realizadas nas décadas anteriores (70 e 80), permaneceriam na primeira metade da década de 90, quando a falta de informatividade encontrada nos textos analisados seria decorrente de não terem sido alteradas, na escola, as condições em que se produziam os textos escritos.

Assim, para Pereira (1990), uma das causas dos problemas de redação seria a fragmentação do texto, em contexto escolar, para atividades que não possibilitariam ao aluno construir para si a noção de unidade textual composta de elementos inter-relacionados. O autor afirma que os problemas observados na escola se apresentariam já há bastante tempo, e seriam decorrentes de não se haver substituído um ensino descontextualizado, que não consideraria a cultura do aluno ao propor temas que deveria tratar em sua redação, por outra prática, supostamente menos opressiva, que não mais corrigiria o texto produzido de modo a não tolher a criatividade de seu produtor. Dentre as causas dos problemas de escrita, segundo Pereira (1990), estaria a interpretação apressada de princípios que seriam veiculados inclusive pelas então "recentes Propostas Curriculares" (SÃO PAULO, 1986), o que levaria à preocupação com o conteúdo em detrimento da forma, promovendo a permissividade e tornando "coisa do passado" o cuidado com aspectos relativos à norma.

Para o autor, também estaria na origem do problema o fato de o aluno escrever para cumprir a tarefa que lhe foi apresentada, utilizando-se de estratégias de preenchimento (em referência às considerações de Lemos (1977)), ou baseandose em imagens do escrito que lhe atribuem caráter de erudição (em referência às ideias de Pécora (1977)). A presença de clichês estaria associada à falta de dizer do aluno e à sua impossibilidade de posicionar-se criticamente frente aos fatos, o que teria relação com as características do contexto social e ideológico do país, bem como da sociedade capitalista, tais como apontadas por Orlandi e Guimarães (1985), em que o aluno se veria "[...] compelido a uma determinação excessiva da exterioridade, podendo produzir alguns sentidos e não outros." (PEREIRA, 1990, p.88). Considera também o autor que o jovem seria preparado socialmente para a passividade, o que impediria a defesa de argumentos ou "a ação particular de um sujeito de linguagem".

Também Moreira (1991) aponta para o fato de as redações com problemas de avanço de informações, caracterizadas pela mera somatória de frases não 
articuladas entre si, representarem estratégias dos vestibulandos para cumprir a tarefa que lhes foi dada e preencher o espaço da folha em branco (em referência também ao trabalho de Lemos (1977)). Após apresentar e discutir os conceitos de coesão e coerência (evidenciando a prevalência da segunda sobre a primeira - no sentido de que os recursos coesivos se realizam como efeitos das necessidades de coerência), e as metarregras de boa formação textual propostas por Charolles (1985), a autora discute a questão da informatividade no que esta se relaciona com a progressão, o avanço da informação em um enunciado, e com os modos como a progressão temática não se construiria textualmente na redação escolar (referindo o que já teria sido anteriormente apontado por Lemos (1977), Pécora (1980) e Rocco (1981)).

O mesmo processo de acionamento da memória discursiva sobre escrita escolar é observado na pesquisa de Duarte (1992), que refere os trabalhos de Savioli (1988), Rocco (1981) e Barros (1985) pelo que tratam sobre a suposta crise na linguagem e os modos como se relacionam com ela aqueles que de uma maneira ou de outra têm o ensino como uma de suas preocupações. Os problemas encontrados não seriam, segundo a autora, próprios às classes menos privilegiadas, mas se encontrariam em outros lugares da sociedade, mesmo os mais privilegiados, e estariam relacionados com o processo de escolarização formal. A relação entre sucesso/fracasso escolar e nível sócio-econômico é discutida, na sequência, com base nas ideias de Bernstein sobre os códigos sociais, o que recupera um movimento teórico importante no período de emergência da escrita escolar em objeto dos estudos acadêmicos: Duarte (1992) se coloca contrariamente às interpretações que se fizeram da obra do autor de modo que se associasse a elas a ideologia do déficit cultural e linguístico. Labov (1984) é referido para contrapor a noção de déficit linguístico, apontando-se para o fato de que diferenças não implicariam em deficiências.

À proposta do bidialetalismo funcional, fundada nas ideias de Labov, bem como à teoria da reprodução de Bourdieu e Passeron (1970), a autora refere também Snyders (1977) e Soares (1986), que apresentam perspectivas progressistas ou transformadoras para a escola. Ao final, Duarte (1992) afirma aproximar-se então da perspectiva de Soares (1986) ao considerar que o político é constitutivo da ação do professor, mas a ele soma a necessidade de conhecimentos teóricos e práticos específicos que habilitem ao professor exercer sua vontade política.

A referência à associação do social e do político a questões de ensino orienta também o trabalho de Pernambuco (1993), para quem a necessidade de pesquisar sobre a produção escrita de alunos se originaria nos problemas detectados principalmente por ocasião das redações de vestibular, que indicariam falhas no trabalho escolar de ensino da escrita. A redação de vestibular teria assumido, então, " [...] a função de filtro sócio-econômico, responsável pelo impedimento do 
acesso à universidade de milhares de alunos que já concluíram os estudos de $2^{\circ}$ grau." (PERNAMBUCO, 1993, p.21).

O autor se apresenta discordante da tese de que crianças menos favorecidas socialmente apresentariam déficits cognitivos. Porém, a partir de citação de Halliday (1976) sobre as contribuições de Basil Bernstein para a consideração das relações entre língua e sociedade, se aproxima das propostas deste autor para considerar a existência da distância entre a língua da escola e a das camadas menos favorecidas da população. Concorda então Pernambuco (1993) com Labov (1984), para quem a não apropriação, pelas crianças de classes desfavorecidas, da língua da escola, representaria, de fato, uma questão não de deficiência, mas de diferença linguística. A escola deveria então se responsabilizar por garantir ao aluno os recursos para atuar sobre o mundo.

Segundo Pernambuco (1993), a conclusão possibilitada pelo trabalho de análise das redações que compuseram o corpus de sua pesquisa é a de que o ensino de língua materna não estaria se fazendo de modo a " [...] conduzir o aluno à produção de mensagens escritas expressivas que traduzam espírito crítico, discurso próprio, visão de mundo pessoal, como domínio da língua como forma de ação sobre o outro e sobre o mundo." (PERNAMBUCO, 1993, p.219). Assim, recupera-se referência presente nos primeiros trabalhos publicados sobre escrita escolar, no Brasil, de que o aluno reproduziria o senso comum, clichês, ou o discurso escolar, de modo a preencher o espaço em branco destinado à produção do texto. O objetivo do aluno seria o de cumprir a tarefa proposta pelo professor, o interlocutor a quem se dirige, para ser avaliado, desenvolvendo sua redação como se fosse uma resposta mais alongada a uma questão de prova.

A presença de clichês e o trabalho com o discurso do outro constituem as questões de base da pesquisa de Amaral (1996). A resposta do texto às condições de produção se colocou como uma das problemáticas consideradas, tendo sido selecionadas para compor o corpus do trabalho as redações que se produziram a partir da opção pelo tema "Violência deve ser combatida com violência?". Com base em referencial teórico fundamentado em Análise do Discurso de linha francesa, o objetivo da investigação foi o de encontrar causas da escolha do vestibulando pelo tema em questão e "justificar o uso do 'já-dito' como estratégia discursiva" (AMARAL, 1996, p.8).

Segundo a autora, a opção por trabalhar com textos surgiu da necessidade de responder a questionamentos comuns entre alunos sobre a importância de se aprender português. As dúvidas a respeito do tema teriam começado a encontrar respostas no livro O texto na sala de aula, que teria ajudado a compreender melhor "[...] o espaço do aluno, a situação do professor e principalmente o papel da escola, enquanto instituição de ensino." (AMARAL, 1996, p.11). 
Amaral (1996), na análise que faz de redações, referencia suas observações em noções de textualidade, apontando para a falta de informatividade, que, segundo a autora, evidenciaria o uso de estratégias de preenchimento pelo aluno, a fim de cumprir a tarefa que lhe foi imposta, atitude que seria ensinada pela escola, que veicularia imagem de escrita como reprodução de modelos e adaptação do discurso às imagens e circunstâncias que seriam impostas ao escritor. Ao tratar do lugar comum nas redações, refere estudos de Lemos (1977), Pécora (1989), Rocco (1981) e Val (1991), quanto ao que apresentam sobre a questão da circularidade nas redações que analisaram.

Traço comum, portanto, aos trabalhos observados, é a referência às causas e às características dos problemas de redação tais como consideradas em pesquisas desenvolvidas nas décadas de 70 e 80, de que se elegem alguns elementos principais: a menção às estratégias de preenchimento (LEMOS, 1977) e à impossibilidade de estabelecimento de um posicionamento crítico por parte do sujeito (PÉCORA, 1989), que seriam decorrentes de uma crise na linguagem (ROCCO, 1981) associada a diferenças linguísticas e culturais entre a cultura escolar e a cultura que o aluno traz de sua comunidade para a escola. Nota-se, portanto, nos trabalhos observados, a referência a uma memória já então constituída para o discurso acadêmico sobre a escrita escolar. A partir de elementos que compõem essa memória, tratam-se das condições de produção, em contexto escolar, que levariam a que os textos produzidos apresentassem as características encontradas - falta de informatividade, deficiências de progressão, problemas de coesão e coerência -, que seriam a atualização em termos da linguística textual, de problemas detectados por pesquisas realizadas anteriormente - presença de clichês, de frases feitas, de estratégias de preenchimento.

As pesquisas desenvolvidas na década de 90 parecem partir do princípio de que as condições de produção textual na escola não teriam sido alteradas, portanto, de um momento histórico a outro, o que mostraria que a escola não teria se apropriado de recursos teóricos suficientes para tratar, internamente ao contexto escolar, de questões de linguagem trazidas pelos alunos de seus contextos de origem. Assim, os fatos de oralidade se colocariam ante a produção textual do aluno como um elemento que dificultaria a produção adequada do texto escrito.

O par dicotômico oralidade/escrita, que organizou semanticamente o discurso acadêmico sobre escrita escolar na década de 80, no Brasil, para delimitar o contexto intraescolar e o contexto extraescolar, parece funcionar, neste outro momento histórico, para a delimitação entre o acadêmico (que se volta para a escrita escolar com os instrumentos da linguística textual) e o escolar (em que se observa a concorrência entre a oralidade e a escrita, fomentada pelas próprias condições de produção do texto escrito na escola). 
Definem-se, assim, os limites entre os contextos de pesquisa e de ensino, delimitação que organiza o processo de interincompreensão entre um discurso e seu outro, como se observará a seguir.

\section{Sobre a relação oralidade/escrita}

A causa apontada por Pereira (1990) para os problemas encontrados nos textos escolares que analisa se relacionaria à transferência de recursos da modalidade oral para a modalidade escrita, problemas recorrentemente apontados em pesquisas desenvolvidas sobre o tema nas décadas de 70 e 80.

No mesmo sentido, o trabalho de Duarte (1992) se inicia apontando para as especificidades que fazem mais difícil a aquisição da escrita, se comparada com a aquisição da modalidade oral. Aprender a ler e a escrever seria um processo mais tenso que aprender a falar, dado o status que possuiria a escrita socialmente, o que diferenciaria as expectativas sociais sobre sua aquisição. Outro elemento diferenciador do processo de aquisição das modalidades seria referente ao contexto próprio a cada uma delas: o contexto da modalidade oral se caracterizaria por ser situacional, e não apenas verbal; o contexto próprio à modalidade escrita seria "simplesmente textual" (DUARTE, 1992, p.22), e qualquer informação sobre o que se está lendo ou escrevendo deveria ser encontrada no próprio texto. Observa-se, nesta última proposição, a perspectiva de que a unidade textual garante autonomia à noção de texto e ao trabalho de pesquisa e de ensino em torno do objeto textual.

Segundo Duarte (1992), a espontaneidade com que se aprenderia fora da escola seria interrompida, em seu interior, por sua organização de tempo e de espaço, sujeitos a normas para a correção dos comportamentos. Tem-se, assim, circunscrito o contexto escolar em sua especificidade.

Nesse contexto, a redação escolar estaria "a meio caminho do escrito e do oral", como considera, em outra pesquisa, Pernambuco (1993, p.140). O autor aponta para o fato de as críticas da sociedade recaírem sobre as produções escritas dos alunos, sendo elas mais condescendentes no que se refere à modalidade oral. Esse fato indicaria que o que se consideraria na avaliação das redações de vestibular seria não o conteúdo, mas a forma. Apenas os meios acadêmicos observariam os textos considerando-os como unidades de sentido, pois mesmo os meios de comunicação utilizariam uma norma linguística que simularia ser culta, mas que seria, de fato, popular: tratar-se-ia de uma "norma média", uma combinação de traços de uma e outra norma.

Partindo do fato da anterioridade da oralidade em relação à escrita, seria necessário, segundo Pernambuco (1993), considerar a relação estreita entre as 
modalidades no processo de ensino da produção textual, considerando-se a interpenetração entre uma modalidade e outra. O poder e a utilidade conferidos à escrita socialmente são considerados também com base em estudos (como o de Goody e Watt (1963)) a respeito das possibilidades cognitivas e organizacionais oferecidas pela escrita.

Aponta o autor para a complexidade na aquisição de ambas as modalidades, mas informa sobre o fato de que se adquire a modalidade oral de forma espontânea, intuitiva e natural, referindo sua relação mais próxima com a matriz biológica. À escola caberia desenvolver esse conhecimento já adquirido de modo a possibilitar a aquisição e desenvolvimento da modalidade escrita, para o que estaria demonstrando sua incapacidade no ensino de língua materna (PERNAMBUCO, 1993), como demonstrado por vários trabalhos de pesquisa, que são referidos na sequência do texto de Pernambuco (1993), em que não apenas textos de alunos, mas também de professores apontariam para a complexidade que é a produção de uma redação.

A relação entre oralidade e escrita é também considerada por Petroni (1994) em seu trabalho. A autora propôs-se a apresentar alternativa para a avaliação do texto escrito na escola, analisando textos narrativos, descritivos e dissertativos com o objetivo de observar o uso realizado de recursos da linguagem oral e da linguagem escrita, e a funcionalidade dos recursos usados para a construção da coesão e coerência textuais. A análise teria evidenciado o uso de recursos coesivos próprios da modalidade oral na organização de gêneros próprios à cultura escrita.

Num sentido semelhante, Petroni (1994), ao tecer então considerações a respeito das diferenças entre linguagem escrita e linguagem oral (referindo, dentre outros autores, Halliday (1989) e Koch e Travaglia (1989, 1991)), aponta para as características próprias à produção do texto falado e para a funcionalidade que nesse processo assumem ocorrências geralmente consideradas como problemas como fragmentações, repetições, hesitações, rupturas, dentre outros -, quando a referência para julgá-las é a estabilidade do produto textual escrito, esquecidas as marcas da fluência também constituinte de sua elaboração no interior de um processo interacional, dialógico.

Apenas o trabalho de Amaral (1996), do corpus constituído para a presente investigação, não tematizou em sua pesquisa as relações oralidade/escrita, o que talvez se deva ao referencial teórico adotado, a Análise do Discurso de linha francesa, que se volta mais especificamente para o tratamento de documentos escritos.

O par dicotômico oralidade/escrita, que organizou semanticamente o discurso acadêmico sobre escrita escolar na década de 80, no Brasil, para delimitar o contexto intraescolar e o contexto extraescolar, parece funcionar, neste outro 
momento histórico, para a delimitação entre o acadêmico (que se volta para a escrita escolar com os instrumentos da linguística textual) e o escolar (em que se observa a concorrência entre a oralidade e a escrita, fomentada pelas próprias condições de produção do texto escrito na escola). Definem-se, assim, os limites entre os contextos de pesquisa e de ensino, delimitação que organiza o processo de interincompreensão entre um discurso e seu outro, como se observará a seguir.

\section{A proposição de alternativas para o ensino de escrita na escola}

As investigações realizadas na primeira metade da década de 90 se caracterizam por propor alternativas para o ensino da escrita na escola, com base em perspectivas teóricas consideradas interessantes para subsidiar o trabalho pedagógico. Não se encontra, nesses trabalhos, a concorrência de diferentes perspectivas, mas a circunscrição a um determinado referencial.

No corpus de análise deste trabalho, encontraram-se fundamentando as pesquisas observadas cinco diferentes perspectivas teóricas: de base estruturalista; funcionalista; semiótica; pragmática; e discursiva. Como já referido, essas perspectivas se apresentaram associadamente a elementos advindos da linguística textual, com base nos quais se evidenciaram as características presentes nos textos produzidos em contexto escolar, e se atualizaram os modos como foi representada a produção escrita escolar na memória discursiva já então produzida no discurso acadêmico.

Nesse processo, o professor é um dos referentes principais, ora considerado como objeto das considerações, ora considerado como interlocutor projetado da pesquisa. As propostas pedagógicas se realizaram, então, contrapostas às concepções e práticas que prevaleceriam em contexto de ensino e que seriam responsáveis pelos problemas detectados nos textos escritos produzidos pelos alunos.

Nesse sentido, Pereira (1990), adotando perspectiva que nomeia de estruturalista, apresenta uma série de exercícios que possibilitariam aos alunos desenvolver a consciência a respeito dos recursos que a língua proporciona para a comunicação. O professor teria papel importante nesse processo, pois transmitiria ao estudante formas para o aperfeiçoamento da redação "através das inúmeras variações permitidas pela língua na expressão do pensamento", diminuindo a tensão entre ensino de redação e ensino de gramática, pois os recursos gramaticais seriam ensinados com objetivos redacionais (PEREIRA, 1990, p.146).

As características próprias à organização discursiva existente no momento histórico considerado podem ser observadas nas duas hipóteses que Pereira (1990) apresenta em seu trabalho: a primeira, que evidencia a filiação a uma memória 
discursiva já constituída sobre ensino de escrita, aponta que todos os problemas de redação poderiam ser reunidos numa rubrica geral a que denominou "falhas de redação", as quais incluiriam problemas referentes a modalidade e problemas referentes a ordem lexical ou sintática, dificultando o "estabelecimento de relações entre os constituintes do código escrito" (PEREIRA, 1990, p.27-28). A segunda hipótese, que evidencia o modo de interlocução que se estabelece então entre academia e escola, e entre pesquisador e professor, aponta para a possibilidade de elaboração de exercícios pelo pesquisador que auxiliariam o professor a solucionar os problemas geralmente encontrados nas redações de seus alunos.

Os exercícios propostos por Pereira (1990) em suas sugestões pedagógicas seriam tentativas de aproveitar, segundo o autor, as contribuições do estruturalismo linguístico, que seriam largamente usadas para o ensino de língua estrangeira, e, mais recentemente, para o ensino de língua materna. Alerta o autor, entretanto, para o fato de as atividades no ensino de língua não poderem restringir-se apenas a exercícios estruturais, mas que estes deveriam ser combinados com outras atividades. Aponta também para o fato de que as sugestões pedagógicas realizadas teriam sido pautadas pela necessidade de o professor ensinar a língua, e não apenas ensinar a reconhecê-la, de modo a não retirar a escrita da linguagem, e esta da ação intersubjetiva - como já teria apontado por Pécora (1983).

A ação transformadora da escola se faria, então, segundo uma "opção política decisiva" (PEREIRA, 1990, p.29), que envolveria a instrumentalização do aluno das camadas populares, basicamente por meio da aquisição do dialeto-padrão (PEREIRA, 1990) para que pudesse superar sua situação de marginalidade (SOARES, 1986) e superar a crise na linguagem apontada por Rocco (1981). Essas mudanças necessitariam de alterações estruturais na própria escola, e mudanças nas atitudes do professor com relação ao seu papel e ao dos alunos.

É também o trabalho do professor que tematiza Moreira (1991) para tratar, com base em perspectiva funcionalista, do ensino de redação. A autora aponta para a lacuna então existente no país no que se referiria aos estudos sobre progressão temática, que auxiliariam no desenvolvimento da proficiência escrita e seriam importantes para o ensino de redação na escola. Nesse sentido, segundo a autora, os professores deveriam chamar a atenção dos alunos para a necessidade de "evitar a circularidade, a repetição de conteúdos informativos" (MOREIRA, 1991, p.109), o que poderia ser feito mostrando-se aos alunos, sem uso de terminologia técnica, os tipos de progressão temáticas caracterizados pelos estudos da área. Além disso, o ensejo para a utilização de diferentes tipos de progressão temática estaria também na diversificação, pelo professor, dos temas para redação.

Assim, aponta Moreira (1991, p.92), "[...] apenas o domínio formal da articulação tema-rema não é suficiente para garantir a produção de um texto semanticamente interessante.", o que, segundo a autora, indicaria a necessidade de os professores 
se empenharem para que os alunos veiculassem, por meio dos remas, informações relevantes em seus textos, o que os enriqueceria em informatividade. Segundo a pesquisadora, a proposição, pelo professor, de temas para redação que "ensejem o uso dos diferentes tipos de progressão temática" possibilitaria aos estudantes organizarem seus textos de diversas maneiras, ordenando adequadamente as ideias e sua expressão em suas redações, o que aumentaria a proficiência na escrita (MOREIRA, 1991, p.49). A possibilidade de avaliar a progressão temática e a estruturação do texto, pelo aluno, possibilitaria trabalhos de revisão mais eficazes, no sentido de conseguir informatividade, a progressão desta, e a obtenção de coerência. Estaria evidenciada, assim, a "[...] relevância da aplicação pedagógica tanto do princípio de progressão temática como da Análise da Estrutura do Tópico." (MOREIRA, 1991, p.60).

A Análise da Estrutura do Tópico poderia ser usada também para o trabalho de revisão dos rascunhos pelos alunos, ressalvando a autora ser o rascunho não apenas o que seria "passado a limpo", mas uma primeira versão do texto, sobre a qual deveriam ser realizadas tantas intervenções quantas se julgassem necessárias para a obtenção de um texto que expressasse de forma clara e coerente o ponto de vista do autor. Segundo a autora, a familiarização dos alunos com elementos evidenciados pela Análise da Estrutura do Tópico, além da realização de trabalho que tornasse evidente a importância do rema, poderia garantir a produção de redações sem problemas quanto aos processos de progressão temática e ao conteúdo informativo (MOREIRA, 1991).

A pesquisa sobre processos de escrita de estudantes poderia contribuir também, segundo Moreira (1991), para o conhecimento de traços linguísticos responsáveis pelos textos serem considerados bons, em relação à sua formação: com sua identificação, esses traços poderiam ser então ensinados pelos professores.

Dispositivo semelhante ao exposto acima se encontra no trabalho de Duarte (1992) para a proposição da semiótica como recurso para o tratamento de questões de ensino de escrita. Segundo a autora, a escolha desse referencial teórico se justificaria pelo fato de sua abordagem da narrativa, que, enquanto texto figurativo (em oposição, assim, ao dissertativo), estaria presente, em sua diversidade, para todos os tempos e espaços sociais, para todos os grupos na sociedade, transcendendo qualquer juízo de valor. A potencialidade pedagógica que possuiria a narrativa não estaria sendo devidamente explorada na rotina das escolas públicas, em que poderia ser utilizada para se aproximar, inclusive, dos alunos das classes mais pobres, que teriam com ela, a narrativa, uma relação, por princípio, prazerosa. Faltariam, entretanto, ao professor, instrumentos eficazes de análise textual para lidar com o texto narrativo em contexto de ensino (DUARTE, 1992). 
Duarte (1992) tem como ponto central a possibilidade de interferir pedagogicamente, com base na perspectiva da semiótica greimasiana, junto a alunos do primeiro grau, no que se refere à produção de textos. Assim, o trabalho contribuiria para "oferecer ao professor instrumentação didática" (DUARTE, 1992, p.14). A opção pela semiótica greimasiana se faria porque essa perspectiva poderia fornecer instrumentos para o tratamento das várias narrativas, municiando o professor de primeiro grau para o estudo do texto, o que possibilitaria para ele "monitorar as atividades de redação com mais eficiência" (DUARTE, 1992, p.15).

A autora defende, em consonância com as possibilidades teóricas oferecidas pela perspectiva semiótica, que o trabalho na escola se direcione também para os discursos não linguísticos, o que implicaria na revalorização de meios audiovisuais e também no uso do computador. O professor de língua portuguesa necessitaria assim expandir seu objeto de trabalho, que não mais se limitaria ao verbal, mas se definiria em termos de comunicação humana. Os meios de comunicação de massa seriam assim revalorizados. O que impediria a mudança nas práticas de ensino seria a falta de consciência semiótica para o professor (DUARTE, 1992).

A autora afirma, com base nos resultados de sua pesquisa, ser "[...] viável utilizar-se da teoria semiótica greimasiana para embasar um trabalho de produção de texto com alunos da escola básica, mesmo em escolas de periferia." (DUARTE, 1992, p.173). Esclarece que não teve o objetivo de excluir a possibilidade de aplicação de outras teorias, mas tão somente de "testar as possibilidades do modelo" (DUARTE, 1992, p.173).

Duarte (1992) chama a atenção para os avanços obtidos pelas ciências da linguagem e sobre as contribuições dos conhecimentos produzidos para a reorganização das atividades de ensino de língua portuguesa nos vários níveis escolares. Aponta, porém, para o fato de a escola pública básica parecer ignorar esses avanços. Não haveria, segundo a autora, diálogo entre universidade e escola básica, pesquisador e professor da escola pública. Uma saída possível seria a apresentação de propostas de aplicação pedagógica do conhecimento teórico por parte de quem o produz.

Assim, no último capítulo do trabalho apresenta-se uma proposta para prática de redação na escola: trata-se de retomada dos itens desenvolvidos no capítulo anterior, porém segundo estrutura de caráter instrucional, com os pontos a serem desenvolvidos apresentados em sua sequência acompanhados de comentários a respeito dos elementos teóricos e, por vezes, das necessidades de formação do professor e das alterações nas rotinas de sala de aula (o que incluiria não perceber apartadamente o trabalho com leitura, escrita e gramática).

Observa-se, desse modo, que o professor não apenas é referenciado na pesquisa como um dos sujeitos responsáveis pelo processo de ensino na escola, 
mas é considerado também como destinatário das considerações realizadas, uma vez que a ele são direcionadas as contribuições que as perspectivas teóricas que fundamentam as pesquisas poderiam oferecer para o ensino, contribuições que alguns dos trabalhos oferecem já em forma de proposta didática.

No trabalho de Pernambuco (1993), o diálogo com o professor é estruturante da própria pesquisa. Na investigação considerada, a concepção de ensino de língua pelos professores informantes da pesquisa foi investigada com base na resposta dada a questionário oferecido por ocasião da realização de cursos de formação continuada ou inicial de que esses professores participaram. Segundo o autor, ainda que as formações dos professores informantes fossem diversas (no grupo de 85 professores, havia aqueles formados em instituições particulares e públicas, no caso do Estado de São Paulo, e os que estavam em vias de completar sua formação em nível universitário, no caso de professores da região Norte), as respostas dadas ao questionário foram muito semelhantes no que se referia às concepções de ensino de língua apresentadas.

Com base nas respostas obtidas, Pernambuco (1993) apresenta o perfil do professor informante da pesquisa, que se caracterizaria por considerar que o objetivo do ensino de língua portuguesa seria o de levar o aluno a se apropriar da norma culta, que, por sua vez, estaria representada pela gramática normativa. As práticas pedagógicas se organizariam de acordo com a ordem típica apresentada pelos livros didáticos, com uma primeira atividade de leitura, seguida de exposição sobre tópico de gramática e exercícios subsequentes, finalizando, então, com a atividade de redação sugerida pelo livro didático no fechamento da unidade.

Aponta-se ainda: para o fato de o professor ter afirmado não ler muito, mas incentivar seu aluno a ler; para a fragmentação do texto lido em sala de aula e para seu uso para o ensino de gramática; para a orientação por intermédio da oralidade para a produção de redação; para o privilégio do conhecimento gramatical na correção do texto e para a avaliação geral do aluno. O conceito de texto que possuiria o professor seria inadequado, mostrando sérias dificuldades inclusive com a própria expressão escrita, e colaborando para que o aluno assimilasse uma imagem falsa de texto (PERNAMBUCO, 1993). O professor precisaria, então, ser um bom leitor e um bom escritor para poder levar o aluno a se inserir nas práticas de leitura e de escrita.

O ensino estaria assim pautado numa concepção estática de linguagem, que a conceberia como um conjunto de formas fixas a serem apreendidas pelos alunos. Os professores estariam trabalhando segundo o princípio de que "tudo está pronto no terreno da língua" (PERNAMBUCO, 1993, p.123). A essa perspectiva, o autor apresenta a alternativa oferecida pela teoria da enunciação, que possibilitaria colocar em primeiro plano o uso da língua, e, a partir dele, tratar de elementos próprios à ordem formal da linguagem. Essa alternativa supriria inclusive a lacuna 
ocasionada pelo fato de a linguística de base estrutural ou gerativa não terem se aproximado do professor e da sala de aula, ou ainda de não possibilitarem o trabalho além das formas linguísticas. A teoria da enunciação permitiria privilegiar os indivíduos e o processo de interação, para se "praticar a linguagem, em vez de se ficar apenas falando dela" (PERNAMBUCO, 1993, p.124).

Foram analisadas três redações produzidas por alunos de uma turma de $3^{\circ}$ ano de ensino médio, no último semestre letivo, e, portanto, às vésperas do exame vestibular. Junto às análises, o pesquisador apresenta possibilidades para a alteração das condições de produção do texto na escola, como, por exemplo, a realização de outras formas de ler que o professor poderia desenvolver com os alunos, além de articular as atividades de leitura, escrita e gramática.

O ensino da modalidade escrita deveria se orientar por uma perspectiva enunciativa, e não apenas formalista de linguagem, o que foi defendido pelo autor com base em ideias elaboradas por Benveniste $(1976,1989)$ e Yaguello (1990). A essa perspectiva enunciativa, que possibilitaria perceber o aluno em sua subjetividade e considerar o uso da linguagem para a interação, o posicionamento consciente e a transformação social, se associam as noções elaboradas por Halliday (1976) quanto às funções ideacional, interpessoal e textual, que estariam "perfeitamente integradas no sistema linguístico" e seriam "eminentemente sociais" (PERNAMBUCO, 1993, p.75). O professor, nesse contexto, teria o papel de fornecer aos alunos condições de desenvolver seus recursos expressivos de modo a ter "[...] condições de agir como cidadãos conscientes e críticos do seu papel no mundo." (PERNAMBUCO, 1993, p.236). Para isso, o professor deveria ser um bom leitor, e, com base em sua formação, ser capaz de organizar sua prática de sala de aula de modo a obter os resultados esperados junto a seus alunos.

A referência à alteração das práticas é também um dos pontos fundamentais do trabalho de Petroni (1994), que considera que a alteração das práticas escolares possibilitaria, ao professor, então, outro modo de perceber o texto produzido em sala de aula, encontrando outros modos de avaliá-los que não os característicos da tradição escolar. Nesse sentido, ainda que o trabalho de Petroni (1994) se construa segundo um processo de aproximação em relação ao intraescolar, dado que propõe a realização de experimento em sala de aula, evidencia-se a delimitação do discurso acadêmico em relação ao pedagógico: são as contribuições do primeiro que possibilitam ressignificar os elementos do segundo.

A perspectiva teórica em que se fundamenta a pesquisa em questão é a pragmática, com base na Teoria da Relevância (SPERBER;WILSON, 1986). Segundo essa teoria, a relevância de uma informação nova se faria em função do reforço que implicaria para crenças já existentes, ou, em sentido inverso, em sua contribuição para a alteração dessas crenças: 
[...] os interlocutores tentariam maximizar a relevância de qualquer informação nova, derivando tantos efeitos contextuais quantos possíveis, com o menor esforço de processamento possível e isso pode determinar a escolha de diferentes contextos para interpretação do(s) enunciado(s). (PETRONI, 1994, p.76).

No trabalho de Petroni (1994), a Teoria da Relevância auxiliaria a compreender determinados aspectos dos textos componentes do corpus que não responderam afirmativamente à proposta de redação com base em que se produziram: uma vez que, segundo a teoria em questão, o falante/escritor teria como objetivo sempre maximizar a relevância de sua informação, os textos foram produzidos de modo a realmente contribuir para a ampliação do conjunto de crenças do interlocutor, independentemente de as informações estarem adequadas a um determinado gênero textual.

A autora chama a atenção, porém, para o fato de que tais considerações teóricas sobre a produção do texto falado e do texto escrito, ainda que pudessem receber simpatia de professores que com elas mantivessem contato, não chegariam a exercer influência sobre as práticas escolares, que requereriam do aluno a manifestação por escrito de acordo com a norma padrão da língua escrita (PETRONI, 1994). Assim, estariam relacionados fracasso escolar e origem social, como apontado por Soares (1986).

Em sua investigação, Petroni (1994) propõe-se contrariar as crenças de que os alunos de classes sociais desprivilegiadas apresentariam déficits, porque não saberiam escrever. A análise dos textos escritos produzidos pelos sujeitos da pesquisa mostraria que os alunos seriam capazes de produzir textos coerentes com o tema proposto, ainda que nem sempre segundo os moldes dos gêneros de discurso esperados. Tal fato demonstraria que além dos recursos de coesão para a materialização do texto em sua superfície textual, o que interessaria, em primeiro lugar, seria a coerência. Os resultados da pesquisa poderiam colaborar, então, para a busca de soluções para os problemas do ensino de língua portuguesa, sugerindo "[...] uma alternativa de modificação da atitude do professor dessa disciplina quanto às atividades de redação e correção do texto escrito." (PETRONI, 1994, p.14).

Petroni (1994) aponta então para a necessidade de haver alternativas para a avaliação do texto escrito, em razão de a escola historicamente não proporcionar ao aluno, principalmente os de classes sociais mais desfavorecidas, as condições para o desenvolvimento da linguagem escrita, reduzindo as atividades ao trabalho com metalinguagem (que Geraldi (1985) consideraria como um uso artificial da linguagem), e privilegiando o produto textual e não o processo. Assim, ao privilegiar concepção de linguagem como expressão do pensamento (GERALDI, 1985), e não como forma de interação entre sujeitos socialmente situados, a escola impediria 
que o aluno se apropriasse de conhecimentos próprios à linguagem escrita, obrigando-o a recorrer aos seus conhecimentos da linguagem oral.

Finaliza a dissertação com uma "palavra ao professor de Língua Portuguesa", em que aponta para a "surpresa agradável" proporcionada pela percepção de que mesmo alunos de classe desfavorecida "[...] sabem mais sobre a natureza de um texto escrito do que sonham nossos vãos manuais de gramática." (PETRONI, 1994, p.102). Os alunos teriam demonstrado, assim, "[...] dominar conhecimentos mais importantes que as meras regras gramaticais tão insistente quanto inutilmente surradas na escola." (PETRONI, 1994, p.102).

A disparidade entre teoria e prática e a necessidade de mudanças nas bases teóricas que fundamentam o ensino da escrita na escola é, portanto, recorrente nas investigações desenvolvidas no período estudado. No mesmo sentido, Amaral (1996) refere a relação entre teoria e prática como um incômodo, uma vez que autores proponentes de mudanças para um ensino mais democrático de língua portuguesa seriam conhecidos dos professores, que mesmo veiculando o discurso em questão, desenvolveriam práticas que contrariariam o que proferiam em defesa de um ensino democrático, sensível às diferenças e fundado na interação professor-aluno.

O trabalho de Amaral (1996) tem o objetivo de analisar as condições que envolvem o concurso vestibular e propor mudança na prática pedagógica do professor, o que seria melhor obtido, segundo a autora, desde que compreendidas as causas dos problemas, em razão do que a pesquisa foi reorientada para o estudo das condições de produção dos textos. Assim, sua pergunta recai sobre o porquê de as redações serem "monofônicas", quando todo texto é constitutivamente polifônico.

Para tratar do lugar comum em redações de vestibular, Amaral (1996) se fundamenta em elementos de linguística textual, principalmente nos trabalhos de Halliday e Hasan (1976), quando tratam da repetição como mecanismo coesivo; e de Charolles (1978), quando propõe as quatro meta-regras constitutivas da textualidade (de repetição; de progressão; de não contradição; de relação): dessas, a autora se detém nas duas primeiras, consideradas interessantes para o problema por ela observado. Cita-se ainda Danes (1974), para uma abordagem funcional das redações, observando-se as noções de tema e rema, tópico e comentário. As noções dos referidos autores são então associadas ao trabalho com o jogo de imagens (PÊCHEUX, 1969), no que este poderia contribuir para considerar as escolhas linguísticas dos alunos em função das condições de produção do texto escrito e suas projeções possíveis de interlocutor.

Após retomar a noção de jogo de imagens proposta por Pêcheux (1969), desenvolvida por Osakabe (1979), e apropriá-la para as condições de produção 
do vestibular, a autora aponta para o poder que possui o interlocutor no processo do vestibular, e o modo como coloca em risco a própria constituição do locutor. A monofonia é então o que se produz, dado que o aluno reproduz o que considera ser o modo desejado de um aluno se expressar. A solução para o fato estaria, segundo Amaral (1996), no trabalho intertextual, de modo a possibilitar ao aluno colocar em relação textos seus e de outros, promovendo o diálogo.

A noção de paráfrase é agenciada para observar os modos como determinadas formas se repetem nas redações analisadas. Depois de apresentar diferentes concepções de paráfrase, aproximando-se mais de sua elaboração conceitual pela perspectiva da análise do discurso de linha francesa, a autora apresenta conjuntos de enunciados que se aproximam em suas formulações de modo parafrástico. Segundo Amaral (1996, p.96), o material obtido sugeriria uma monótona repetição, mas também apresentaria "[...] algum trabalho do sujeito, que introduz algo de novo ou de diferente no seu texto." A autora aponta para a possibilidade de produção de texto polifônico com o uso de clichês, o que se realizaria pela colocação de discursos distintos em contraponto.

A autora sugere, por fim, algumas mudanças a serem realizadas no ensino de modo a resolver os problemas da escrita escolar, o que passaria por rever a relação da escola com o vestibular, com este respondendo àquela e não o contrário, como de fato estaria acontecendo; o objetivo seria o de não haver privilégios sociais de acesso à universidade, considerado o lugar dos cursinhos, e que o ensino não se reduzisse a mero treinamento. Além disso, seria necessário promover interação de fato na sala de aula, de modo que o leitor do texto do aluno não se reduzisse à figura do professor avaliador, possibilitando, com isso, que a situação de produção se fizesse menos artificial. A escolha do tema a ser tratado na redação e as restrições de tempo e de espaço para a produção do texto, a que se associaria a impossibilidade de agenciar discursos diversos para a produção de um texto polifônico, seriam fatores a serem revistos, pois neles estariam as causas dos problemas de textos em que, ainda que não se percebesse um sujeito assujeitado, porque faria uso de estratégias para cumprir a tarefa de escrever como usar clichês, por exemplo -, perceber-se-ia, por outro lado, um sujeito que não se posicionaria, mas tentaria manter-se neutro, pois seria isso que acreditaria se esperar dele na escola.

O trabalho de Amaral (1996) estrutura-se semelhantemente aos demais trabalhos que compõe o corpus de análise: caracterizando-se os problemas de redação, cujas causas já teriam sido evidenciadas pelas pesquisas desenvolvidas sobre escrita escolar, no país, nas décadas de 70 e de 80, constrói-se a referência a elementos da linguística textual, com o que se constitui um eixo centrado na ideia de unidade textual. A base constituída pelo recurso à memória discursiva sobre escrita escolar e à perspectiva teórica da linguística textual sustenta o trabalho 
de elaboração teórica das pesquisas, em que uma segunda perspectiva teórica do campo dos estudos linguísticos é agenciada para o tratamento dos dados e para a proposição de alternativas para o ensino de escrita na escola.

A coerência que seria subjacente à perspectiva teórica adotada é então projetada para o trabalho pedagógico, que poderia ter solucionados seus problemas em razão de poderem ser preenchidas lacunas, ou eliminadas falhas decorrentes de práticas docentes fundamentadas em concepções insatisfatórias de linguagem.

A formação do professor é focalizada, constituindo-se ora como objeto das considerações realizadas, ora como destino das propostas de ensino elaboradas pelo pesquisador. Essas proposições direcionadas ao trabalho pedagógico são tematizadas, nos trabalhos observados, também em sua relação com as propostas oficiais de ensino de língua portuguesa. Mantém-se o princípio do distanciamento entre discursos - nesse caso, do acadêmico para com o oficial e o pedagógico. Os problemas no ensino de escrita seriam decorrentes do não suficiente contato do professor com as propostas de mudança em suas práticas de sala de aula, ou da "[...] interpretação apressada de princípios que seriam veiculados inclusive pelas então 'recentes Propostas Curriculares'.", como o aponta Pereira (1990, p.44). Marca-se, desse modo, o distanciamento entre concepções de linguagem e de ensino elaboradas em instâncias acadêmicas e oficiais e aquelas próprias à cultura escolar.

A construção de uma perspectiva de distanciamento em relação aos discursos oficial e pedagógico delimita um exterior para o discurso acadêmico, que ocupa então o espaço do extraescolar. Dessa posição, dialoga com seus outros, definindo as fronteiras que delimitam seu espaço. O distanciamento entre o acadêmico, o escolar e o oficial seria, assim, um índice dos modos como organizadas as relações interdiscursivas, que se caracterizariam por um processo mais coeso de identificação dos discursos. Desse modo, a constituição dos discursos não mais se realizaria com base em sobreposições e compartilhamentos de espaços, como no período de suas emergências, mas segundo processos de delimitação recíproca, segundo o princípio da interincompreensão (MAINGUENEAU, 2005).

\section{Considerações finais}

Nos documentos observados no presente trabalho, a construção do distanciamento entre professor e pesquisador parece ser uma característica do discurso acadêmico sobre escrita escolar (e, talvez, do discurso acadêmico sobre ensino de língua materna, de modo mais geral) no momento histórico em questão. 
A identidade de um e outro sujeito se constrói em enunciados que referem, por exemplo, a falta de diálogo entre Universidade e escola básica, pesquisador e professor da escola pública (DUARTE, 1992).

A figura do professor parece ser o elemento em relação ao qual se referenciam as posições e os limites dos discursos em sua organização no espaço discursivo: ao professor se direcionam os enunciados oficiais, pedagógicos e acadêmicos, e, nessa posição, fala-se dele, ou fala-se para ele, ou, mesmo, fala-se com ele. A ambivalência de sua posição permite aos pesquisadores se movimentarem, e, em seu percurso, redefinir os limites das formações discursivas, agenciando elementos teóricos e constituindo a escrita em objeto de discurso.

A circunscrição da fundamentação teórica, nas investigações realizadas no período, a uma única perspectiva, é outra característica diferenciadora do estado em que se encontrava o discurso acadêmico sobre escrita escolar, na década de 90, no espaço discursivo considerado, em relação a seus estados anteriores, em que diferentes perspectivas teóricas concorriam para a constituição da escrita escolar em objeto de discurso.

As pesquisas sobre escrita escolar desenvolvidas então se produzem num momento em que a apropriação de saberes para a fundamentação de propostas pedagógicas se realiza de modo a projetar o princípio de coerência que deveria estar subjacente à perspectiva teórica escolhida para subsidiar a proposição de elementos para o ensino de língua portuguesa. A coerência, característica da base teórica adotada para a elaboração das propostas pedagógicas, se projetaria, por sua vez, para o trabalho em sala de aula, solucionando problemas de ensino resultantes de falhas decorrentes das insuficiências dos saberes existentes em contexto de ensino.

A constituição da escrita escolar em objeto de pesquisa, no período e no espaço discursivo observados, parece se fazer, assim, com base na contraposição entre o princípio de coerência que seria próprio a determinada perspectiva teórica - adotada para fundamentar o trabalho de investigação e a proposição de possibilidades para o trabalho pedagógico —, e a ausência da atuação desse princípio em contexto de ensino, o que produziria lacunas, que deveriam ser preenchidas; falhas, que deveriam ser reparadas; defasagens, que deveriam ser corrigidas.

A coerência teórica em contexto de pesquisa e a insuficiência teórica em contexto escolar representam os pontos de tensionamento para a constituição da escrita escolar em objeto de pesquisa no momento histórico observado, movimento que possui um terceiro elemento (externo) projetado na figura de uma interlocução virtual (dado que as pesquisas realizadas possuiriam como horizonte de leitura primeiro o contexto acadêmico em que se produziram): 
os sujeitos em contexto de ensino - dentre eles, principalmente, o professor. Esse elemento externo assume o estatuto ambíguo que pode ser atribuído à terceira pessoa do discurso, que ocuparia, por vezes, a posição de referente; por vezes, a posição de pessoa do discurso (CERVONI, 1989). O estatuto ambíguo atribuído à terceira pessoa, nas pesquisas realizadas no período em observação, parece ser o que possibilita sua (dessa terceira pessoa) inserção na cena que se constrói: ocupa, nela, a posição de elemento de que se fala, mas também a de sujeito a quem (virtualmente) se fala - permanecendo sua possibilidade de manifestação apenas projetada (um impeditivo de que assuma de fato a posição de segunda pessoa do discurso).

Neste dispositivo que se constrói com a polarização entre contexto de pesquisa e contexto de ensino, associada à projeção de uma instância a que se atribui o estatuto de interlocutor virtual, o pesquisador se desloca de um polo a outro, e, dirigindo as considerações que realiza a um interlocutor projetado, que pode ocupar também a posição de objeto dessas considerações, constitui, nesse movimento, a escrita escolar em objeto de pesquisa.

PIETRI, E. Linguistic studies and the constitution of discursive objects: the theoretical framework of text linguistics as a reference to the theoretical analytical treatment of school writing. Alfa, São Paulo, v.58, n.2, p.371-400, 2014.

- ABSTRACT: In this paper, we present the results of a research that aimed to investigate the process of constitution of school writing as object of linguistic studies. The corpus was composed of dissertations and thesis developed in Postgraduate Programs of Public Universities from São Paulo, Brazil, during the first years of the 1990s. Following the theoretical approach affiliated to French Discourse Analysis, some interdiscursive relations were observed in order to recognize the characteristics of academic discourse about school writing. Data analysis revealed that, in the historical moments chosen for this research, a discursive memory was already constituted, which grounded the definition of themes, concepts and theoretical strategies on the treatment of school writing as an object of discourse. Produced over the decades of 70 and 80, the consolidation of this memory, associated to the stability of the conception of text proposed by text linguistics, allowed the delimitation and the detachment between academic and school contexts. It also showed that elements from text linguistics supported the mobilization of specific theoretical perspectives on language studies for the treatment of school writing as an object of analysis.

- KEYWORDS: Discourse Analysis. Text Linguistics. School Writing.

\section{REFERÊNCIAS}

ADAM, J.-M. A linguística textual: introdução à análise textual dos discursos. Revisão técnica de Luis Passeggi e João Gomes da Silva Neto. São Paulo: Cortez, 2008. 
AMARAL, N. F. G. Clichês em redações de vestibular: estratégia discursiva. 1996. 147f. Dissertação (Mestrado em Linguística) - Instituto de Estudos Linguísticos, Universidade de Campinas, Campinas, 1996.

BARROS, D. L. P. A festa do discurso: teoria do discurso e análise das redações de vestibulandos. 1985. 592f. Tese (Livre-docência em Linguística) - Faculdade de Filosofia, Letras e Ciências Humanas, Universidade de São Paulo, São Paulo, 1985.

BENVENISTE, E. Problemas de lingüística geral II. São Paulo: Ed. Nacional: Ed. da USP, 1989.

. Problemas de lingüística geral I. São Paulo: Ed. Nacional: Ed. da USP, 1976.

BOURDIEU, P.; PASSERON, J.-C. La reproduction. 1.ed. Lisboa: Moraes, 1970.

BRASIL. Secretaria de Educação Fundamental. Parâmetros Curriculares Nacionais: $1^{\mathrm{a}}$ a $4^{\mathrm{a}}$ séries do ensino fundamental. Brasília: MEC/SEF, 1997.

CERVONI, J. A enunciação. São Paulo: Ática, 1989.

CHAROLLES, M. Text connexity, text coherence and text interpretation process. In: SÖZER, M. (Ed.). Text connexity and text coherence. Hamburg: Buske, 1985. p.1-16.

. Introduction aux problèmes de la cohérence des textes. Langue Française, Paris, n. 38, p.7-14, 1978.

DANES, F. Functional sentence perspective and the organization of text. In: DANES, F. (Ed.). Papers in functional sentence perspective. Prague: Academia, 1974. p.106-128.

DUARTE, J. M. Produção escrita de alunos da escola pública: a possível contribuição da semiótica. 1992. 221f. Tese (Doutorado em Semiótica e Linguística Geral) - Faculdade de Filosofia, Letras e Ciências Humanas, Universidade de São Paulo, São Paulo, 1992.

GERALDI, J. W. Concepções de linguagem e ensino. In: GERALDI, J. W. (Org.). O texto na sala de aula: leitura \& produção. 2.ed. Cascavel: Assoeste, 1985. p.41-48. GOODY, J.; WATT, I. The consequences of literacy. Comparative studies in society and history, New York, v.5, p.304-345, 1963.

HALLIDAY, M. A. K. Spoken and written language. Oxford: University Press, 1989. Estrutura e função da linguagem. In: LYONS, J. (Org.). Novos horizontes em lingüística. São Paulo: Cultrix: EDUSP, 1976. p.134-160.

HALLIDAY, M. A. K.; HASAN, R. Cohesion in English. London: Logman, 1976.

KOCH, I. V. G. O desenvolvimento da Lingüística Textual no Brasil. DELTA, São Paulo, v.15, nesp., 1999. 
KOCH, I. V. G.; TRAVAGLIA, L. C. A coerência textual. São Paulo: Contexto, 1991. A coesão textual. São Paulo: Contexto, 1989.

LABOV, W. Language in the inner city. Philadelphia: University of Pennsylvania Press, 1984.

LEMOS, C. T. G. Redações no vestibular: algumas estratégias. Cadernos de Pesquisa, São Paulo, n.23, p.61-71, 1977.

MAINGUENEAU, D. Gênese dos discursos. Tradução de Sírio Possenti. Curitiba: Criar Edições, 2005.

Novas tendências em Análise do Discurso. Tradução de Freda Indursky. Campinas: Pontes: Ed. da UNICAMP, 1997.

MAINGUENEAU, D. (Org.). Les analyses du discours en France. Langages, Paris, n.117, p.96-111, mars 1995.

MOREIRA,T. M. A progressão temática na redação escolar. 1991. 132f. Dissertação (Mestrado em Linguística Aplicada) - Instituto de Estudos Linguísticos, Universidade de Campinas, Campinas, 1991.

ORLANDI, E.; GUIMARÃES, E. Texto, leitura e redação. São Paulo: SE/CENP, 1985. (Projeto Ipê. Língua Portuguesa, n.3).

OSAKABE, H. Argumentação e discurso político. São Paulo: Kairós, 1979.

PÊCHEUX, M. Análise automática do discurso (AAD-69). In: GADET, F.; HAK, T. (Org.). Por uma análise automática do discurso: uma introdução à obra de Michel Pêcheux. 3.ed. Campinas: Ed. da UNICAMP, 1969. p.61-161.

PÉCORA, A. A. B. Problemas de redação. São Paulo: Martins Fontes, 1989.

PÉCORA, A. A. B. Problemas de redação. São Paulo: Martins Fontes, 1983. . Problemas de redação na universidade. 1980. 121f. Dissertação (Mestrado em Letras) - Instituto de Estudos Linguísticos, Universidade de Campinas, Campinas, 1980.

Redações no vestibular: estudo do período, uma proposta pragmática. Cadernos de Pesquisa, São Paulo, n.23, p.29-36, 1977.

PEREIRA, R. F. Contribuição para o estudo de problemas de redação. 1990. $231 \mathrm{f}$. Tese (Doutorado em Letras) - Faculdade de Ciências e Letras, Universidade Estadual Paulista, Assis, 1990.

PERNAMBUCO, J. A redação escolar: análise dos efeitos da escolaridade. 1993. 328f. Tese (Doutorado em Educação) - Faculdade de Educação, Universidade de São Paulo, São Paulo, 1993. 
PETRONI, M. R. A organização do texto escrito por alunos do $1^{\circ}$ grau. 1994. 118f. Dissertação (Mestrado em Linguística) - Instituto de Estudos Linguísticos, Universidade de Campinas, Campinas, 1994.

PIETRI, E. A constituição da escrita escolar em objeto de pesquisas acadêmicas. Cadernos de História da Educação, Uberlândia, v.11, n.1, p.107-130, jan./jun. 2012a.

A oralidade, a escrita e as condições de produção de textos na escola: a constituição da escrita escolar em objeto de investigações acadêmicas. Perspectiva, Florianópolis, v.30, p.573-602, maio/ago. 2012b.

A constituição da escrita escolar em objeto de análise dos estudos lingüísticos. Trabalhos em Lingüística Aplicada, Campinas, v.46, n.2, p.283-297, jul./dez. 2007a.

. Circulação de saberes e mediação institucional em documentos oficiais: análise de uma proposta curricular para o ensino de língua portuguesa. Currículo sem Fronteiras, [s.1.], v.7, n.1, p.263-283, jan./jun. 2007b.

ROCCO, M. T. F. Crise na linguagem: a redação no vestibular. São Paulo: Mestre Jou, 1981.

SÃO PAULO (Estado). Secretaria Estadual de Educação. Proposta Curricular para o Ensino de Língua Portuguesa: $1^{\circ}$ grau. São Paulo: SE/CENP, 1986.

Guias Curriculares para o ensino de 1º grau. São Paulo: Cerhupe, 1975.

SAVIOLI, F. R. O ensino da leitura: um projeto gradual e ininterrupto. 1988. $343 f$. Tese (Doutorado em Semiótica e Linguística Geral) - Faculdade de Filosofia, Letras e Ciências Humanas, Universidade de São Paulo, São Paulo, 1988.

SNYDERS, G. Escola, classe e luta de classes. Lisboa: Moraes, 1977.

SOARES, M. B. Linguagem e escola: uma perspectiva social. São Paulo: Ática, 1986.

SPERBER, D.; WILSON, D. Communication and cognition. Cambridge: Harvard University Press, 1986.

VAL, M. G. C. Redação e textualidade. Martins Fontes: São Paulo, 1991.

YAGUELLO, M. Alice no país das maravilhas: para compreender a lingüística. Tradução de Maria José Figueiredo. Lisboa: Editorial Estampa, 1990.

Recebido em janeiro de 2013

Aprovado em maio de 2013 